\author{
JURNAL PENJAMINAN MUTU \\ LEMBAGA PENJAMINAN MUTU \\ INSTITUT HINDU DHARMA NEGERI \\ DENPASAR
}

Volume 4 Nomor 2 Agustus 2018

ISSN : 2407-912X (Cetak)

ISSN : 2548-3110 (Online)

http://ejournal.ihdn.ac.id/index.php/JPM

\title{
PEMANFAATAN TIGA JALUR PENDIDIKAN DALAM PENGEMBANGAN MUTU PEMBELAJARAN ETIKA DAN MORAL
}

\author{
Oleh \\ Anak Agung Raka Asmariani \\ Institut Hindu Dharma Negeri Denpasar \\ rakaasmariani@ihdn.ac.id
}

Diterima 31 Juli 2018, direvisi 14 Agustus 2018, diterbitkan 31 Agustus 2018

\begin{abstract}
Each;Every birth that happened is appearance a new stupidity. This matter will experience of a transform through process instruction of science. Education band play a part very important. One of the important problem in life in this fatherland is moral and ethics, Education bands represent medium education of child giving an enrichment in moral and ethics in society. Teaching moral value and ethics better more is having the character example of. Do something better then just say of words. that multifarious Value Moral kinds of, including loyalitas, benefaction, honorary, truth, respek, sociability, integrity, justice, cooperation
\end{abstract}

\section{Keywords: Ethics, Education, Moral}

\section{PENDAHULUAN}

Pergeseran paradigma pendidikan tak semuanya membawa keuntungan. Selalu ada kelemahan, selalu ada celah kekurangan. Semula kita menganut paham bahwa pendidikan untuk membentuk karakter budi pekerti anak didik, namun pada gilirannya kemudian kita menganut paham pendidikan untuk melakukan transfer pengetahuan pada siswa. Kini kita sepaham, pendidikan diarahkan demi pemberdayaan siswa. Akan tetapi, mengapa kekerasan dan dehumanisasi justru kian mengeras, merasuki kehidupan geng remaja yang terselubung organisasi, ataupun tindakan-tindakan yang merugikan kepentingan umum yang terorganisir oleh lembaga-lembaga yang memiliki legalitas hukum yang kuat.

Bersamaan dengan gairah mencapai mutu pendidikan, kita mengadopsi Total Quality Management, yang dicangkok dari dunia industri. Kesalahan itu terjadi ketika kita menjadi pragmatis, bahkan sangat pragmatis, untuk mencapai mutu pendidikan yang mengutamakan kepuasan "pelanggan" (siswa, orang tua siswa, dan masyarakat). Siswa dinyatakan lulus dan berprestasi dengan standar angka-angka. Siswa melanjutkan pendidikan ditentukan pula dengan angkaangka dan kemampuan menanggung biaya pendidikan. 
Tak ada lagi pembinaan budi pekerti. Tak ada lagi pembinaan moralitas. Tak ada lagi religiusitas. Lenyap sudah eksistensi para siswa sebagai manusia berbudaya. Bahkan, penalaran, sikap kritis, humanisme, lenyap dibentak ke bawah telapak kaki. Terjadilah kejutan-kejutan penyimpangan yang dilakukan kaum terdidik, di antaranya kekerasan geng yang dilakukan para siswa. Betapa tak berdaya moralitas guru, orang tua, dan masyarakat. Kekerasan yang dilakukan kaum terdidik terhadap yuniornya demi tuntutan eksistensialisme remaja, menandai krisis jati diri dan moralitas, terselubung mata rantai geng yang merasuk antargenerasi. Ini buah kegagalan pendidikan keluarga dan masyarakat, yang mencorengkan aib di lingkungan sekolah. Apalagi kini dunia pendidikan kita telah terjebak pada paham pragmatisme itu ketika mengutamakan hasil (angka) yang diraih dengan jalan pintas (drill), dan bukan pemberdayaan nilai-nilai dan pengetahuan dalam penerapan kehidupan sehari-hari untuk menghadapi arus kuat goncangan kebudayaan di masa sekarang dan yang akan datang.

\section{PEMBAHASAN}

\section{Pendidikan Sebagai Kegiatan Ilmu dan Seni}

Masalah pendidikan mikro yang menjadi focus disini khususnya ialah dasar dan landasan pendidikan serta landasan ilmu pendidikan yaitu manusia atau sekelompok kecil manusia dalam fenomena pendidikan.

\subsection{Pendidikan dalam Praktek Memerlukan teori}

Alangkah pentingnya kita berteori dalam praktek di lapangan pendidikan karena pendidikan dalam praktek harus dipertanggungjawabkan. Tanpa teori dalam arti seperangkat alasan dan rasional yang konsisten dan saling berhubungan maka tindakan-tindakan dalam pendidikan hanya didasarkan atas alasan-alasan yang kebetulan, seketika dan aji mumpung. Hal itu tidak boleh terjadi karena setiap tindakan pendidikan bertujuan menunaikan nilai yang terbaik bagi peserta didik dan pendidik. Bahkan pengajaran yang baik sebagai bagian dari pendidikan selain memerlukan proses dan alasan rasional serta intelektual juga terjalin oleh alasan yang bersifat moral. Sebabnya ialah karena unsur manusia yang dididik dan memerlukan pendidikan adalah makhluk manusia yang harus menghayati nilai-nilai agar mampu mendalami nilai-nilai dan menata perilaku serta pribadi sesuai dengan harkat nilai-nilai yang dihayati itu.

Kita baru saja menyaksikan pendidikan di Indonesia gagal dalam praktek berskala makro dan mikro yaitu dalam upaya bersama mendalami, mengamalkan dan menghayati Pancasila. Lihatlah bagaimana usaha nasional besar-besaran selama 20 tahun (1978-1998) dalam P-7 (Pembinaan Pendidikan Pelaksanaan Pedoman Penghayatan dan Pengamalan Pancasila) berakhir kita nilai gagal menyatukan bangsa untuk memecahkan masalah nasional suksesi kepresidenan secara damai tahun 1998, setelah krisis multidimensional melanda dan memporakporandakan hukum dan perekonomian negara mulai pertengahan tahun 1997, bahkan sejak 27 Juli 1996 sebelum kampanye Pemilu berdarah tahun 1997. itu adalah contoh pendidikan dalam skala makro yang dalam teorinya tidak pas dengan Pancasila dalam praktek diluar ruang penataran. Mungkin penatar dan petatar dalam teorinya ber-Pancasila tetapi didalam praktek, sebagian besar telah cenderung menerapkan Pancasila Plus atau Pancasila Minus atau kedua-duanya. Itu sebabnya harus kita putuskan bahwa P-7 dan P-4 tidak dapat dipertanggungjawabkan, setidak-tidaknya secara moral dan sosial.

Mari kita kembali berprihatin sesuai ucapan Dr. Gunning yang dikutip Langeveld (1955). "Praktek tanpa teori adalah untuk orang idiot dan gila, sedangkan teori praktek hanya untuk orang-orang jenius". Ini berarti bahwa sebaiknya pendidikan tidak dilakukan kecuali oleh orang-orang yang mampu bertanggung jawab secara rasional, sosial dan moral. Sebaliknya apabila pendidikan dalam praktek dipaksakan tanpa teori dan alasan yang memadai maka hasilnya adalah bahwa semua pendidik dan peserta didik akan merugi. Kita merugi karena tidak 
mampu bertanggung jawab atas esensi perbutan masing-masing dan bersama-sama dalam pengamalan Pancasila. Pancasila yang baik dan memadai, konsisten antara pengamalan (lahiriah) dan penghayatan (psikologis) dan penataan nilai secara internal. Dalam hal ini kita bukan menyaksikan kegiatan (praktek) pendidikan tanpa dasar teorinya tetapi suatu praktek pendidikan nasional tanpa suatu teori yang baik.

\subsection{Landasan Sosial dan Individual Pendidikan}

Pendidikan sebagai gejala sosial dalm kehidupan mempunyai landasan individual, sosial dan cultural. Pada skala mikro pendidikan bagi individu dan kelompok kecil berlangsung dalam skala relatif tebatas seperti antara sesama sahabat, antara seorang guru dengan satu atau sekelompok kecil siswanya, serta dalam keluarga antara suami dan isteri, antara orang tua dan anak serta anak lainnya. Pendidikan dalam skala mikro diperlukan agar manusia sebagai individu berkembang semua potensinya dalam arti perangkat pembawaanya yang baik dengan lengkap. Manusia berkembang sebagai individu menjadi pribadi yang unik yang bukan duplikat pribadi lain. Tidak ada manusia yang diharap mempunyai kepribadian yang sama sekalipun keterampilannya hampir serupa. Dengan adanya individu dan kelompok yang berbeda-beda diharapkan akan mendorong terjadinya perubahan masyarakat dengan kebudayaannya secara progresif. Pada tingkat dan skala mikro pendidikan merupakan gejala sosial yang mengandalkan interaksi manusia sebagai sesama (subyek) yang masing-masing bernilai setara. Tidak ada perbedaan hakiki dalam nilai orang perorang karena interaksi antar pribadi (interpersonal) itu merupakan perluasan dari interaksi internal dari seseorang dengan dirinya sebagai orang lain, atau antara saya sebagai orang kesatu (yaitu aku) dan saya sebagai orang kedua atau ketiga (yaitu daku atau-ku; harap bandingkan dengan pandangan orang Inggris antara I dan me).

Pada skala makro pendidikan berlangsung dalam ruang lingkup yang besar seperti dalam masyarakat antar desa, antar sekolah, antar kecamatan, antar kota, masyarakat antar suku dan masyarakat antar bangsa. Dalam skala makro masyarakat melaksanakan pendidikan bagi regenerasi sosial yaitu pelimpahan harta budaya dan pelestarian nilai-nilai luhur dari suatu generasi kepada generasi muda dalam kehidupan masyarakat. Diharapkan dengan adanya pendidikan dalam arti luas dan skala makro maka perubahan sosial dan kestabilan masyarakat berangsung dengan baik dan bersama-sama. Pada skala makro ini pendidikan sebagai gejala sosial sering terwujud dalam bentuk komunikasi terutama komunikasi dua arah. Dilihat dari sisi makro, pendidikan meliputi kesamaan arah dalam pikiran dan perasaan yang berakhir dengan tercapainya kemandirian oleh peserta didik. Maka pendidikan dalam skala makro cenderung dinilai bersifat konservatif dan tradisional karena sering terbatas pada penyampaian bahan ajar kepada peserta didik dan bisa kehilangan ciri interaksi yang afektif.

\subsection{Pendidikan Memadu Jalinan Antara Ilmu dan Seni}

Adanya aspek-aspek lahiriah, psikologis dan rohaniah seperti disebut tadi mengisyaratkan bahwa manusia dalam fenomena (situasi) pendidikan adalah paduan antara manusia sebagai fakta dan manusia sebagai nilai. Tiap manusia bernilai tertentu yang bersifat luhur sehingga situasi pendidikan memiliki bobot nilai individual, sosial dan bobot moral. Itu sebabnya pendidikn dalam praktek adalah fakta empiris yang syarat nilai berhubung interaksi manusia dalam pendidikan tidak hanya timbal balik dalam arti komunikasi dua arah melainkan harus lebih tinggi mencapai tingkat maniusiawi seperti saya atau siswa mendidik diri sendiri atas dasar hubungan pribadi dengan pribadi (higher order interactions) antar individu dan hubungan intrapersonal secara afektif antara saya (yaitu I) dan diriku (diri sendiri yaitu my self atau the self).

Adapun manusia sebagai fakta empriris tentu meliputi berbagai variabel dan hubungan variabel yang terbatas jumlahnya 
dalam telaah deskriptif ilmu-ilmu. Sedangkan jumlah variabelnya amat banyak dan hubungan-hubungan antara variabel amat kompleks sifatnya apabila pendidik memelihara kualitas interaksinya dengan peserta didik secra orang perorang (personal). Sepeti dikatakan tentang siswa belajar aktif oleh Phenix (1958:40), yaitu : "It possible to conceive of teacher and student as one and same person and the self taught person as one who direct his own development through an internal interaction between the self as I and the self as me on the other hand, it is usual for one teacher to teach many students simultaneously. In that even the quality of the interaction may become generalized and impersonal, or it may, by appropriate means, retain its person to person character".

Seperti dikatakan secara ilmiah oleh NL. Gage (1978:20), "Scientific method can contribute relationships between variaboles, taken two at a time and even in the form of interactions, three or perhaps four or more at a time. Beyond say four, the usefulness of what science can give the teacher begins to weaken, because teacher cannot apply, at least not without help and not on the run, the more complex interactions. At this point, the teacher as an artist must step in and make clinical, or artistic, judgement about the best ways to teach."

Atas dasar pokok-pokok pikiran tentang aspek lahiriah, psikologis dan rohaniah dari manusia dalam fenomena pendidikan maka pendidikan dalam praktek haruslah secara lengkap mencakup bimbingan, mendidik, mengajar dan pengajaran. Dalam fenomena yang normal peserta didik dapat didorong agar belajar aktif melalui bimbingan dan mengajar. Tetapi adakalanya dalam situasi kritis siswa perlu meniru cara guru yang aktif belajar sendiri. Itu sebabnya perundangundangan pendidikan kita sebenarnya perlu diluruskan, pada satu sisi agar upaya mendidik terjadi dalam keluarga secara wajar, disisi lain agar pengajaran disekolah meliputi dimensi mendidik dan mengajar. Lagi pula bahwa diferensisasi dan fungsi sekolah sebagai lembaga pendidikan perlu ditentukan utamanya harus melakukan pengajaran dan mengelola kurikulum formal sebagai aspek spesialisasinya agar beroperasi efisien. Sedangkan konsep pendidikan yang juga mencakup program latihan (UU. No. 2/1989 Pasal 1 butir ke-1) adalah suatu konstruk yang amat luas dilihat dari perspektif sekolah sebagai lembaga pendidikan formal.

Maka konsep pendidikan yang memerlukan ilmu dan seni ialah proses atau upaya sadar antar manusia dengan sesama secara beradab, dimana pihak kesatu secara terarah membimbing perkembangan kemampuan dan kepribadian pihak kedua secara manusiawi yaitu orang perorang. Atau bisa diperluas menjadi makro sebagai upaya sadar manusia dimana warga maysrakat yang lebih dewasa dan berbudaya membantu pihak-pihak yangkurang mampu dan kurang dewasa agar bersama-sama mencapai taraf kemampuan dan kedewasaan yang lebih baik (Phenix, 1958:13), Buller, 1968:10). Dalam arti ini juga sekolah laboratorium akan memerlukan jalinan praktek ilmu dan praktek seni. Sebaliknya butir 1 pasal 1, UU No. 2 /1989 kiranya kurang tepat sehingga tentu sulit menuntut siswa ber CBSA padahal guru belum tentu aktif belajar, mengingat definisi pendidikan yang makro, yaitu :

"Pendidikan ialah usaha sadar untuk mempersiapkan peserta didik melalui kegiatan bimbingan, pengajaran dan atau latihan bagi peranannya dimasa yang akan datang".

Kiranya konsep pendidikan yang demikian kurang mampu memberi isi kepada tujuan dan semangat Bab XIII UUD 1945 yang merujuk bidang pendidikan sebagai amanah untuk mewujudkan keterkaitan erat antara sistem pengajaran nasional dengan kebudayaan kebangsaan. Karena itu dalam lingkup pendidikan menurut skala mikro dan abstark yang lebih makro, pendidik harus juga peduli dengan aspek etis (moral) dan estetis dari pengalamannya berinteraksi dengan peserta didik selain aspek pengetahuan, kebenaran dan perilaku yang disisyaratkan oleh konsep pendidikan menurut undangundang tadi. Hal ini sesuai dengan pandangan Ki Hajar Dewantara (1950) sebagai berikut : 
"Taman Siswa mengembangkan suatu cara pendidikan yang tersebut didalam Among dan bersemboyan 'Tut Wuri Handayani' (mengikuti sambil mempengaruhi). Arti Tut Wuri aialah mengikuti, namun maknanya ialah mengikuti perkembangan sang anak dengan penuh perhatian berdasarkan cinta kasih dan tanpa pamrih, tanpa keinginan menguasai dan memaksa, dan makna Handayani ialah mempengaruhi dalam arti merangsang, memupuk, membimbing, memberi teladan gar sang anak mengembangkan pribadi masing-masing melalui disiplin pribadi".

Demikian bagi Ki Hajar Dewantara pendidikan pada skala mikro tidak terlepas dari pendidikan dalam arti makro, bahkan disipilin pribadi adalah tujuan dan cara dalam mencapai disiplin yang lebih luas. Ini berarti bahwa landasan pendidikan terdapat dalam pendidikan itu sendiri, yaitu factor manusianya. Dengan demikian landasanlandasan pendidikan tidak mesti dicari diluar fenomena (gejala) pendidikan termasuk ilmuilmu lain dan atau filsafat tertentu dari budaya barat. Oleh karena itu data ilmu pendidikan tidak tergantung dari studi ilmu psikologi, fisiologi, sosiologi, antropologi ataupun filsafat. Lagi pula konsep pengajaran (yang makro) berdasarkan kurikulum formal tidak dengan sendirinya bersifat inklusif dan atau sama dengan mengajar. Bahkan dalam banyak hal pengajaran itu tergantung hasilnya dari kualitas guru mengajar dalam kelas masingmasing. Sudah barang tentu asas Tut Wuri Handayani tidak akan menjadikan pengajaran identik dengan sekedar upaya sadar menyampaikan bahan ajar dikelas kepada rombongan siswa mengingat guru harus berhamba kepada kepentingan siswanya.

\section{Bagaimana Mengajarkan Etika Dan Nilai Moral}

Dalam mengajarkan etika dan nilai moral sebaiknya lebih bersifat contoh, pepatah mengatakan bahwa tindakan lebih baik dari kata-kata. Lutan mengatakan Nilai Moral itu beraneka macam, termasuk loyalitas, kebajikan, kehormatan, kebenaran, respek, keramahan, integritas, keadilan, kooperasi, tugas dll. Lebih lanjut dikatakan ada 4 nilai moral yang menjadi inti dan bersifat universal yaitu : (contoh dalam dunia olah raga)

\section{Keadilan.}

Keadilan ada dalam beberapa bentuk ; distributif, prosedural, retributif dan kompensasi. Keadilan distributif berarti keadilan yang mencakup pembagian keuntungan dan beban secara relatif. Keadilan prosedural mencakup persepsi terhadap prosedur yang dinilai sportif atau fair dalam menentukan hasil. Keadilan retributif mencakup persepsi yang fair sehubungan dengan hukuman yang dijatuhkan bagi pelanggar hukum. Keadilan kompensasi mencakup persepsi mengenai kebaikan atau keuntungan yang diperoleh penderita atau yang diderita pada waktu sebelumnya.

Seorang wasit bila ragu memutuskan apakah pemain penyerang berada pada posisi off-side dalam sepakbola, ia minta pendapat penjaga garis. Semua pemain penyerang akan protes, meskipun akhirnya harus dapat menerima, jika misalnya wasit dalam kasus lainnya memberikan hukuman tendangan penalti akibat pemain bertahan menyentuh bola dengan tanganya, atau sengaja menangkap bola di daerah penalti. Tentu saja ia berusaha berbuat seadil mungkin. Bila ia kurang yakin, mungkin cukup dengan memberikan hukuman berupa tendangan bebas.

\section{Kejujuran.}

Kejujuran dan kebajikan selalu terkait dengan kesan terpercaya, dan terpercaya selalu terkait dengan kesan tidak berdusta, menipu atau memperdaya. Hal ini terwujud dalam tindak dan perkataan.

Semua pihak percaya bahwa wasit dapat mempertaruhkan integritasnya dengan membuat keputusan yang fair. Ia terpercaya karena keputusannya mencerminkan kejujuran.

\section{Tanggung Jawab.}

Tanggung jawab merupakan nilai moral penting dalam kehidupan bermasyarakat. Tanggung jawab ini adalah pertanggungan perbuatan sendiri. Seorang 
atlet harus bertanggung jawab kepada timnya, pelatihnya dan kepada permainan itu sendiri. Tanggung jawab ini merupakan nilai moral terpenting dalam olahraga.

\section{Kedamaian}

Kedamaian mengandung pengertian : a)tidak akan menganiaya, b)mencegah penganiayaan, c) menghilangkan penganiayaan, dan d)berbuat baik. Bayangkan bila ada pelatih yang mengintrusksikan untuk mencederai lawan agar tidak mampu bermain?

Freeman dalam buku Physical Education and Sport in A cahanging Society menyarankan 5 area dasar dari etika yang harus diberikan yaitu : 1) Keadilan dan persamaan, 2) Respek terhadap diri sendiri. 3) Respek dan pertimbangan terhadap yang lain,

4) Menghormati peraturan dan kewenangan ,

5) Rasa terhadap perspektif atau nilai relatif. (Freeman,2001;210)

1. Keadilan dan Persamaan

Anak didik atau atlet adalah mengharapkan perlakuan yang adil dan sama. Anak didik ingin sebuah kesempatan untuk belajar yang sama. Seringkali anak didik yang di bawah ratarata dalam olahraga diabaikan.

2. Respek terhadap diri sendiri

Pelajar atau atlet membutuhkan respek terhadap diri sendiri dan imej positif tentang dirinya untuk menjadi sukses. Pelatih dan pengajar yang melatih semua anak didiknya dengan sama mengambil langkah tepat dalam setiap arahnya agar anak didiknya merasa dirinya penting dan layak dimata pengajarnya.

3. Rasa hormat dan kepedulian terhadap orang lain.

Pelajar dan atlet membutuhkan rasa hormat kepada orang lain, apakah teman sekelasnya, lawan bertanding, guru ataupun pelatihnya. Mereka perlu belajar tentang bagaimana pentingnya memperlakukan orang lain dengan hormat.

4. Menghormati peraturan dan kewenangan Pelajar dan atlet perlu menghormati kewenangan dan peraturan, karena tanpa kedua hal ini suatu perhimpunan tidak akan berfungsi

2. Rasa terhadap perspektif atau nilai relatif Dengan adanya rasa belas kasih, murid dapat diberi semangat untuk melihat lawan sebagai kawan dalam permainan, samasama bernilai, sama-sama patut menerima penghargaan. Keadilan melibatkan tidak keberpihakan, sama-sama tanggung jawab. Ketangkasan dalam olahraga melibatkan berusaha secara intens menuju sukses. Integritas memungkinkan seseorang untuk membuat kesalahan pada yang lain, sebagai contoh meskipun tindakannya negatif penerimannya oleh wasit, teman satu tim ataupun fans.

\subsection{Mutu Pendidikan Dan Ajaran Agama Hindu Dalam Pengembangan Etika \\ Mutu pendidikan merupakan sebuah} jalan untuk melakukan pengajaran ataupun penanaman nilai-nilai, baik itu melalui pendidikan Formal, pendidikan non formal ataupun pendidikan informal. Selain melakukan proses pengajaran terhadap ilmu pengetahuan dan keterampilan jalur-jalur pendidikan tersebut juga harus dapat memberikan pengajaran dan penanaman nilai-nilai, sikap moral dan etika yang berlaku di masyarakat. Hal tersebut dapat tercermin dalam beberapa ajaran agama Hindu yakni; Catur Asrama

Catur Asrama terdiri atas dua kata yakni "Catur", yang berarti empat dan "Asrama", berarti tahapan atau jenjang.Jadi Catur Asrama artinya empat jenjang kehidupan yang harus dijalani untuk mencapai moksaa tau catur asrama dapat pula diartikan sebagai empat lapangan atau tingkatan hidup manusia atas dasar keharmonisan hidup dimana pada tiap- tiap tingkat kehidupan manusia diwarnai oleh adanya ciri- ciri tugas kewajiban yang berbeda antara satu masa (asrama) dengan masa lainnya, tetapi merupakan kesatuan yang tak dapat dipisahkan. 


\section{KESIMPULAN}

Seorang calon pendidik hanya dapat melaksanakan tugasnya dengan baik jika memperoleh jawaban yang jelas dan benar tentang apa yang dimaksud pendidikan. Jawaban yang benar tentang pendidikan diperoleh melalui pemahaman terhadap unsur-unsurnya, konsep dasar yang melandasinya, dan wujud pendidikan sebagi sistem.

Dalam ajaran agama Hindu ada beberapa unsur dan konsep dasar yang dapat memberikan gambaran tentang pendidikan dan pengembangan etika yaitu ajaran catur asrama. Jika dicermati dan amati korelasi dan nilai dari ketiga ajaran ini terhadap perjalanan kehidupan manusia sangat relevan sekali dalam pembentukan dan perkembangan etika dalam kehidupan manusia.

\section{DAFTAR PUSTAKA}

Bogdan \& Biklen (1982) Qualitative Research For Education. Boston MA: Allyn Bacon

Deese, J (1978) The Scientific Basis of the Art of Teaching. New York : Colombia University-Teachers College Press

Gordon, Thomas (1974) Teacher Effectiveness Training. NY: Peter $h$. Wydenpub

Henderson, SVP (1954) Introduction to Philosophy of Education.Chicago : Univ. of Chicago Press
Hidayat Syarief (1997) Tantangan PGRI dalam Pendidikan Nasional. Makalah pada Semiloka Nasional Unicef-PGRI. Jakarta: Maret,1997

Highet, G (1954), Seni Mendidik (terjemahan Jilid I dan II), PT.Pembangunan

Kemeny,JG, (1959), A Philosopher Looks at Science, New Hersey, NJ: Yale Univ.Press

Ki Hajar Dewantara, (1950), Dasar-dasar Perguruan Taman Siswa, DIY:Majelis Luhur

Ki Suratman, (1982), Sistem Among Sebagai Sarana Pendidikam Moral Pancasila, Jakarta:Depdikbud

Langeveld, MJ, (1955), Pedagogik Teoritis Sistematis (terjemahan), Bandung, Jemmars

Lestari, I. A. P. S. (2018). Penerapan Metode Pembelajaran Diskusi Dan Resitasi Dalam Meningkatkan Hasil Belajar Pendidikan Agama Hindu Siswa Kelas Iv Sd Negeri 2 Tumbu Karangasem. Jurnal Penjaminan Mutu, 4(1), 58-66.

Liem Tjong Tiat, (1968), Fisafat Pendidikan dan Pedagogik, Bandung, Jurusan FSP FIP IKIP Bandung

Sudharta, MA. , Prof. Dr. Tjok. (2003), Slokantara (Untaian Ajaran Etika), Paramitha Surabaya

Wiratmaja, Drs. G.K. Adia ,(1975), Etika (Tata Susila Hindu Dharma), Sekjen PHDI Pusat. 